editorial

3 Mit Nikotin, Glimmerfaktor oder Grillhähnchengeschmack

Ist die e-Zigarette Sargnagel oder Rettungsanker? J. de Zeeuw, Köln

aufgefallen
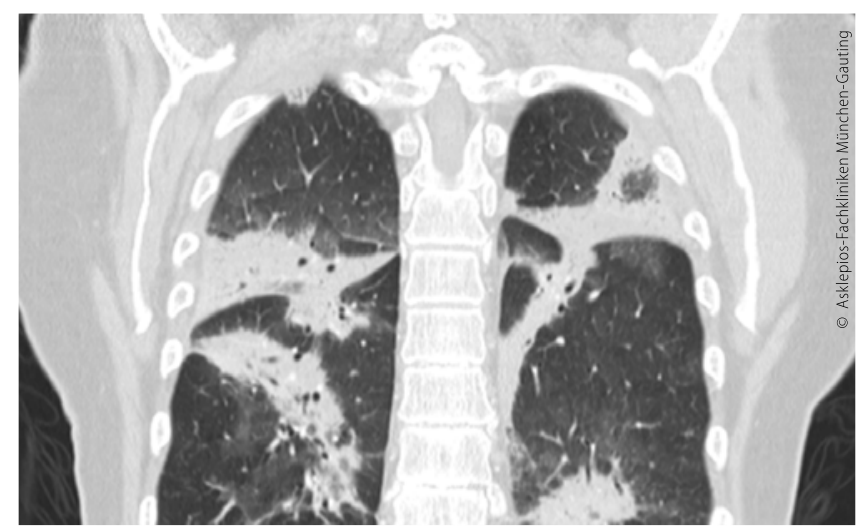

6 Kryptogene organisierende Pneumonie (COP)

Vorsicht Rezidivgefahr!

F. Fliedner und W. Gesierich, Gauting

journal club

8 Übersicht der referierten Studien

zertifizierte fortbildung

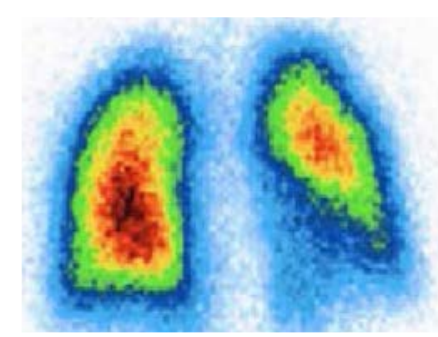

35 Erkennen und behandeln

Chronisch thromboembolische pulmonale Hypertonie K. Gutjahr, Leipzig

40 CME-Fragen pulmonale Hypertonie fortbildung

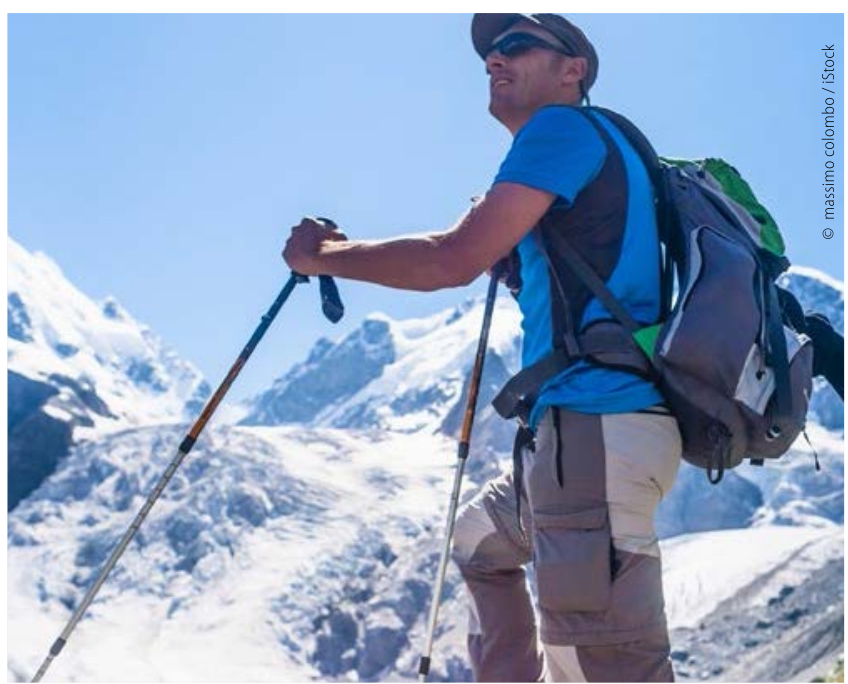

41 (Patho-)Physiologie angewandt Krank durch Höhe - Prophylaxe und Therapie S. Sorichter

aktuell

50 8. Pneumologische Praxistage Tabakentwöhnung: Kurz und bündig

\section{Asthma bronchiale}

- Bei über 30-Jährigen versagt die Therapie häufiger - Asthma bei Kindern: Viel öfter Behandlungsfehler als gedacht

rubriken

58 infopharm

63 impressum

\section{Beihefter}

\section{Medizin Report aktuell \\ COPD \\ Hoher Patientennutzen durch \\ kombinierte Bronchodilatation S. 54 \\ Nicht-kleinzelliges Lungenkarzinom (NSCLC) \\ PD-1-Inhibitor Nivolumab beim fortgeschrittenen \\ Lungenkrebs zugelassen S. 56}

